\title{
Tomographical Findings in Adult Patients Undergoing Endoscopic Sinus Surgery Revision
}

\author{
Jan Alessandro Socher ${ }^{1}$ Jonas Mello ${ }^{2}$ Barbara Batista Baltha ${ }^{2}$ \\ ${ }^{1}$ Department of Otorhinolaryngology, Universidade Regional de \\ Blumenau (Furb), Blumenau, SC, Brazil \\ 2 Medical Students, Furb, Blumenau, SC, Brazil \\ Address for correspondence Jan Alessandro Socher, Department of \\ Otorhinolaryngology, Furb, Rua Antonio da Veiga 140, Blumenau, SC \\ 89030-903, Brazil (e-mail: jan_socher@yahoo.com.br).
}

Int Arch Otorhinolaryngol 2018;22:73-80.

\begin{abstract}
Introduction Many patients undergoing functional endoscopic sinus surgery still have an uncontrolled clinical disease in the late post-operative period. Up to $11.4 \%$ of the patients will require a revision surgery. Findings such as the residual uncinated process and the lateralization of the middle turbinate were considered by some studies as being responsible for failure in the primary surgery.

Objectives To describe the tomographical findings in adult patients undergoing revision endoscopic sinus surgery, the profile of those patients, and verify the mucosal thickening level of the paranasal sinus.

Methods Data were collected from medical records and computed tomography reports of 28 patients undergoing revision sinus surgery on a private service in the city of Blumenau between 2007 and 2014. The score of Lund-Mackay was used to verify the mucosal thickening level.

Results Among the 28 patients, 23 were reoperated once, 3 were reoperated twice, and 2 were reoperated 3 times. The most relevant findings were mucosal thickening of the maxillary sinus (89.28\%), deviated septum (75\%), thickening of the ethmoid (50\%) and sphenoidal sinuses (39.28\%), and pneumatization of the middle turbinate

Keywords

- sinusitis

- otorhinolaryngologic surgical procedures

- reoperation

(39.28\%). The average obtained in the Lund-Mackay score was 5.71, with most patients classified in the lower range of punctuation.

Conclusion The analysis of the computed tomography scans showed persistent structures that may be responsible for the failure of the primary surgery. Computed tomography is a useful tool to plan the surgery and quantify the post-operative success.
\end{abstract}

\section{Introduction}

Chronic rhinosinusitis (CRS) is a common condition in the population. There are not practical statistics about this disease in Brazil, but in the US it is believed that $~ 14 \%$ of adults are affected by CRS. ${ }^{1}$ Most patients have good results with clinical treatment combining antibiotics, decongestants, mucolytics and steroids. ${ }^{2}$ Functional endoscopic sinus surgery (FESS) has been established as one of the main methods in the treatment of CRS refractory to medical therapy, and has been considered the preferred procedure for these cases. ${ }^{1,3}$

With the popularity of this technique among otolaryngologists, FESS has been increasingly performed. ${ }^{4,5}$ The advance of technology in recent years enabled many improvements in otorhinolaryngology surgery. Despite the increasingly received

October 11, 2016

accepted after revision

January 22, 2017

published online

April 24, 2017
DOI https://doi.org/

10.1055/s-0037-1601417. ISSN 1809-9777.
Copyright (c) 2018 by Thieme Revinter

Publicações Ltda, Rio de Janeiro, Brazil
License terms

(요 (1) $\Theta \circledast$ 
sophisticated image techniques and the improvements in endoscopic surgery, there is still a significant number of failures in the postoperative period of FESS. A recent study found that $42.1 \%$ of patients undergoing FESS still had an uncontrolled clinical disease in the late post-operative period. $^{6}$

In cases in which symptoms of the disease remain after the performance of FESS, the first choice should be clinical treatment with antibiotics and steroids. If there is continuity of the symptoms, computed tomography (CT) is indicated in an attempt to locate the source of the infection. When an anatomic abnormality responsible for the failure of the primary surgery is found, revision endoscopic sinus surgery (RESS) may be indicated. ${ }^{7}$ The rate of patients undergoing FESS who require reoperation is significant, and studies indicate rates such as $11.4 \%$ and $7.9 \%$ according to the researched location. 6,8

The CT is an extremely important aspect when dealing with FESS. Besides helping plan the surgery, with the CT, physicians are able to identify and quantify the success of the results in the post-operative period. ${ }^{9}$ The Lund-Mackay score (LMS) is a widely used method for staging CSR by CT analysis. It is the most accepted method for research purposes, and it is the first choice for staging chronic sinusitis using a CT scan. ${ }^{1,9,10}$ The most frequent tomographical findings after FESS found by Khalil et al (2011) were residual cells in the frontal recess and in the posterior/anterior ethmoid, and obstruction of the sphenoid ostial and residual uncinate processes. The presence of these anatomical structures may suggest the reason behind the persistence or recurrence of rhinosinusitis. ${ }^{11}$

The objectives of this study were to describe the tomographical findings and the profile of adult patients undergoing RESS, and to verify the level of mucosal thickening in the paranasal sinuses.

\section{Method}

This retrospective study analyzed patients treated in a private clinic in the city of Blumenau, in the state of Santa Catarina, Brazil. The medical records and the preoperative CT scans of the paranasal sinuses and the nasal cavity of patients undergoing RESS were analyzed. The patients studied were reoperated between January 2007 and December 2014. Adult patients that were symptomatic after FESS and who had to be submitted to RESS were included in the study. Patients without all necessary data in their medical records, patients without a CT scan analyzed by a radiologist, and patients younger than 20 years old on the date that the CT was performed were excluded.

Data collection happened between December 2014 and February 2015. After the first analysis, 33 patients were selected. Five patients were removed from the study, two because they did not have the CTscan attached to the medical record, two because they could not be found to agree to their participation, and one who refused to participate. Thus, this study population was of 28 patients. All of them agreed with their participation in this study and signed the informed consent form.
The tomographical findings and the data necessary to calculate the LMS were verified in the reports of the CT scans. The CT scans and their reports were not done in the same clinic or analyzed by the same radiologist. Therefore, before the inclusion of the tomographical findings as results of this study, the CT scan images were reviewed by an otorhinolaryngologist. All patients in this study were submitted to a CT of the paranasal sinuses and nasal cavity as a preoperative examination before the RESS. None of the patients was previously submitted to FESS in the same service in which the RESS was performed.

The following information related to the profile of the patients were collected: gender; age; number of reoperations; and interval between surgeries. The CT findings were classified according to the anatomical region or structure where they belong, which are: the nasal septum; the inferior turbinate; the middle nasal turbinate; the superior turbinate; the osteomeatal complex; the uncinate process; the maxillary sinus; the ethmoid sinus; the sphenoid sinus; and the frontal sinus.

To verify the thickening level of the mucosa from the paranasal sinuses, the LMS was used. This tool analyzed the following anatomical structures: the frontal sinus; the maxillary sinus; the sphenoid sinus; the anterior portion of the ethmoidal sinus; 5 ) the posterior portion of the ethmoid sinus; and the osteomeatal complex. Both sides of these structures receive grades ranging from 0 to 2 . The score was 0 when no abnormalities were found, 1 when a partial opacification was found, and 2 if total opacification was found. The exception is the osteomeatal complex, which only received the grade 0 when it was not occluded, and 2 when it was occluded. The grades were based on the appearance of each structure on the CT of the paranasal sinuses. Finally, the score of each side and the total of the patient were calculated.

Data were collected, listed, organized and analyzed using the software Microsoft Office Excel 2013 (Redmond, Washington, US). This same software was also used to calculate the standard deviation (SD), the mean and the median. This study was approved by the Ethics Committee Universidade Regional de Blumenau (under number 879433 , approved on November 20, 2014).

\section{Results}

Among the 28 patients analyzed, 11 (39.29\%) were female, and 17 (60.71\%) were male. The average age was 37.32 years, and the median was 36.5 years (SD: 10.24). The lower and higher ages were 20 and 61 years old respectively. It was also found that 23 patients $(82.14 \%)$ were reoperated once, 3 patients $(10.72 \%)$ were reoperated twice, and 2 patients (7.14\%) required reoperation 3 times. The mean number of reoperations was 1.25 (SD: 0.58). The interval between operations was not possible to determine in four patients because of the absence of accurate information in their medical records. The interval between the primary surgery and the reoperation was observed in 24 patients. It presented a variation from 1 to 17 years, with a mean of 5.66 years (SD: 4.68). The interval between the first and second reoperations 
was observed in 3 patients, and it ranged from 1 to 5 years, with a mean of 3.33 years (SD: 2.08 ). It was possible to check the interval between the second and third reoperations in only one patient, and it was two years. All of the data on the profile and the sinonasal surgical history can be seen in -Table 1 .

The findings of the preoperative CT scans were separated according to the related anatomical structure, as shown in -Table 2. In the nasal septum area, 21 patients (75\%) with deviated septum, 3 patients (10.71\%) with septal perforation, and 1 patient (3.57\%) with mucosal thickening along the nasal septum were identified. No abnormalities were found in 6 patients (21.42\%). In the inferior nasal turbinate area, 2 patients $(7.14 \%)$ with obliteration of the inferior meatus, 1 patient $(3.57 \%)$ with a partial reduction of the volume, and 1 patient (3.57\%) with signs of total resection were identified. No abnormalities were found in 24 patients (85.71\%). In the middle nasal turbinate area, 11 patients (39.28\%) with signs of pneumatization, 3 patients (10.71\%) with signs of partial resection, 3 patients (10.71\%) with middle nasal turbinate lateralization, and 2 patients (7.14\%) with mucosal thickening were identified. No abnormalities were found in 11 patients (39.28\%). In the osteomeatal complex, 5 patients (17.35\%) with obliteration of the middle meatus, 1 patient (3.57\%) with signs of resection, 1 patient (3.57\%) without osteomeatal units, and 1 patient $(3,57 \%)$ with polyps related to the osteomeatal units were identified. No signs of manipulation were found in 21 patients (75\%). In the uncinated process area, 2 patients (7.14\%) with signs of resection and 26 patients (92.85\%) with the usual morphology and insertion were identified.

In the maxillary sinus area, 25 patients (89.28\%) with mucosal thickening, 3 patients $(10.71 \%)$ with calcification inside the sinus, 2 patients (7.14\%) with residual Haller cells, 1 patient $(3,57 \%)$ with signs of previous sinus surgery, and 1 patient (3.57\%) with resection of the anterior walls were identified. No abnormalities were found in 3 patients
(10.71\%). In the ethmoidal sinus area, 14 patients (50\%) with mucosal thickening, 1 patient $(3.57 \%)$ with residual ethmoidal cells, and 1 patient (3.57\%) with a retention cyst were identified. No abnormalities were found in 13 patients (46.42\%). In the sphenoid sinus area, 11 patients (39.28\%) with mucosal thickening, 4 patients (14.28\%) with obliteration of the sphenoethmoidal recess, 1 patient (3.57\%) with obliteration of the sphenoethmoidal cells (Onodi cells), 1 patient (3.57\%) with enlargement of the drainage pathways, and 1 patient (3.57\%) with signs of periosteitis were identified. No abnormalities were found in 17 patients (60.71\%). In the frontal sinus area, 8 patients (28.57\%) with mucosal thickening, 7 patients (25\%) with obliteration of the frontal recesses, 2 patients $(7.14 \%)$ with complete obliteration, 1 patient $(3,57 \%)$ with osteoma, 1 patient $(3.57 \%)$ with nondeveloped sinus, and 1 patient (3.57\%) with signs of pneumatization of the interfrontal sinus were identified. No signs of manipulation were found in 18 patients (64.28\%).

The LMS results can be seen in - Tables 3 and 4. The general mean in the 28 patients studied was of 5.7143 (SD: 4.6096), ranging between 1 and 19 points. The right side scores had a mean of 2.8571 (SD: 2.2886), varying from 0 to 9 . And the left side had a mean of 2.8571 (SD: 2.3838), varying from 1 to 10 . The score of the maxillary sinus on the right side had a mean of 0.8214 (SD: 0.4755 ), varied between 0 and 2 , and $21.43 \%$ of patients scored $0,75 \%$ scored 1 , and $3.57 \%$ scored 2 . The score of the maxillary sinus on the left side had a mean of 0.8928 (SD: 0.3149 ), varied between 0 and 1 , and $10.71 \%$ of the patients scored 0 , and $89.29 \%$ scored 1 . The score of the anterior ethmoid sinus on the right side had a mean of 0.5357 (SD: 0.6372), varied between 0 and 2, and $53.57 \%$ of patients scored $0,39.29 \%$ scored 1 , and $7.14 \%$ scored 2 . The score of the anterior ethmoid on the left side had a mean of 0.5357 (SD: 0.6929 ), varied between 0 and 2 , and $57.14 \%$ of patients scored $0,32.14 \%$ scored 1 , and $10.71 \%$ scored 2 .

Table 1 Information about the profile and sinonasal surgical history $(n=28)$

\begin{tabular}{|c|c|c|c|c|c|}
\hline & $\mathrm{N}$ & $\%$ & Mean & Variation & $\begin{array}{l}\text { Standard } \\
\text { Deviation }\end{array}$ \\
\hline \multicolumn{6}{|l|}{ Gender } \\
\hline Male & 17 & 60.71 & & & \\
\hline Female & 11 & 39.29 & & & \\
\hline Age (years) & & & 37.32 & $20-61$ & 10.24 \\
\hline Number of reoperations & & & 1.25 & $1-3$ & 0.58 \\
\hline One reoperation & 23 & 82.14 & & & \\
\hline Two reoperations & 3 & 10.72 & & & \\
\hline Three reoperations & 2 & 7.14 & & & \\
\hline \multicolumn{6}{|l|}{ Interval between operations (years)* } \\
\hline Primary surgery/1st reoperation & 24 & & 5.66 & $1-17$ & 4.68 \\
\hline 1st reoperation/2nd reoperation & 3 & & 3.33 & $1-5$ & 2.08 \\
\hline 2 nd reoperation/3th reoperation & 1 & & 2 & & \\
\hline
\end{tabular}

Note: ${ }^{*}$ For the time interval between operations, $n=24$. 
76 Tomographical Findings in Patients Undergoing Endoscopic Sinus Surgery Revision Socher et al.

Table 2 Preoperative CT findings in patients undergoing RESS $(n=28)$

\begin{tabular}{|c|c|c|c|}
\hline $\begin{array}{l}\text { Anatomical } \\
\text { structure }\end{array}$ & Tomographical findings & $\mathbf{N}$ & $\%$ \\
\hline \multirow[t]{4}{*}{ Nasal septum } & Deviated septum & 21 & 75 \\
\hline & Septal perforation & 3 & 10.71 \\
\hline & Mucosal thickening along the nasal septum & 1 & 3.57 \\
\hline & No abnormalities or signs of previous manipulation & 6 & 21.42 \\
\hline \multirow{4}{*}{$\begin{array}{l}\text { Inferior nasal } \\
\text { turbinate }\end{array}$} & Obliteration of the inferior meatus & 2 & 7.14 \\
\hline & Partial volume reduction & 1 & 3.57 \\
\hline & Signs of resection & 1 & 3.57 \\
\hline & No abnormalities or signs of previous manipulation & 24 & 85.71 \\
\hline \multirow{5}{*}{$\begin{array}{l}\text { Middle nasal } \\
\text { turbinate }\end{array}$} & Signs of pneumatization & 11 & 39.28 \\
\hline & Signs of resection & 3 & 10.71 \\
\hline & Lateralization & 3 & 10.71 \\
\hline & Mucosal thickening & 2 & 7.14 \\
\hline & No abnormalities or signs of previous manipulation & 11 & 39.28 \\
\hline \multirow{5}{*}{$\begin{array}{l}\text { Osteomeatal } \\
\text { complex }\end{array}$} & Obliteration of the middle meatus & 5 & 17.85 \\
\hline & Signs of resection & 1 & 3.57 \\
\hline & Absence of osteomeatal units & 1 & 3.57 \\
\hline & Polyps related to osteomeatal units & 1 & 3.57 \\
\hline & No abnormalities or signs of previous manipulation & 21 & 75 \\
\hline \multirow{2}{*}{$\begin{array}{l}\text { Uncinate } \\
\text { process }\end{array}$} & Residual & 2 & 7.14 \\
\hline & Usual morphology and insertion & 26 & 92.85 \\
\hline \multirow[t]{6}{*}{ Maxillary sinus } & Mucosal thickening & 25 & 89.28 \\
\hline & Calcification inside the sinus & 3 & 10.71 \\
\hline & Residual Haller cells & 2 & 7.14 \\
\hline & Resection of the anterior walls & 1 & 3.57 \\
\hline & Signs of previous sinus surgery & 1 & 3.57 \\
\hline & No abnormalities or signs of previous manipulation & 3 & 10.71 \\
\hline \multirow[t]{4}{*}{ Ethmoidal sinus } & Mucosal thickening & 14 & 50 \\
\hline & Residual ethmoidal cells & 1 & 3.57 \\
\hline & Retention cyst & 1 & 3.57 \\
\hline & No abnormalities or signs of previous manipulation & 13 & 46.42 \\
\hline \multirow[t]{6}{*}{ Sphenoidal sinus } & Mucosal thickening & 11 & 39.28 \\
\hline & Obliteration of the sphenoethmoidal recess & 4 & 14.28 \\
\hline & Obliteration of sphenoethmoidal cells (Onodi cells) & 1 & 3.57 \\
\hline & Enlargement of the drainage pathways & 1 & 3.57 \\
\hline & Signs of periostitis & 1 & 3.57 \\
\hline & No abnormalities or signs of previous manipulation & 17 & 60.71 \\
\hline \multirow[t]{7}{*}{ Frontal sinus } & Mucosal thickening & 8 & 28.57 \\
\hline & Obliteration of the frontal recesses & 7 & 25 \\
\hline & Complete obliteration & 2 & 7.14 \\
\hline & Non-developed sinus & 1 & 3.57 \\
\hline & Osteoma & 1 & 3.57 \\
\hline & Pneumatization of the interfrontal sinus & 1 & 3.57 \\
\hline & No abnormalities or signs of previous manipulation & 18 & 64.28 \\
\hline
\end{tabular}

Abbreviations: $\mathrm{CT}$, computed tomography; RESS, revision endoscopic sinus surgery. 
Table 3 Collective results of the LMS $(n=28)$

\begin{tabular}{|l|l|l|l|l|l|l|l|}
\hline & Side & Mean & Variation & $\mathbf{0}(\%)$ & $\mathbf{1}(\%)$ & $\mathbf{2}$ (\%) \\
\hline Maxillary sinus & Right & 0.8214 & $0-2$ & 21.43 & 75 & 3.57 & 0.4755 \\
\hline & Left & 0.8928 & $0-1$ & 10.71 & 89.29 & 0 & 0.3149 \\
\hline Anterior ethmoid & Right & 0.5357 & $0-2$ & 53.57 & 39.29 & 7.14 & 0.6372 \\
\hline & Left & 0.5357 & $0-2$ & 57.14 & 32.14 & 10.71 & 0.6929 \\
\hline Posterior ethmoid & Right & 0.5357 & $0-2$ & 57.14 & 32.14 & 10.71 & 0.6929 \\
\hline & Left & 0.4827 & $0-2$ & 60.71 & 28.57 & 10.71 & 0.6876 \\
\hline Sphenoidal sinus & Right & 0.3214 & $0-1$ & 67.86 & 32.14 & 0 & 0.4755 \\
\hline & Left & 0.3214 & $0-1$ & 67.86 & 32.14 & 0 & 0.4745 \\
\hline Frontal sinus & Right & 0.3571 & $0-2$ & 67.86 & 28.57 & 3.57 & 0.5587 \\
\hline & Left & 0.3928 & $0-2$ & 67.86 & 25 & 7.14 & 0.6288 \\
\hline Osteomeatal complex & Right & 0.2857 & 0 and 2 & 85.71 & - & 14.29 & 0.7127 \\
\hline & Left & 0.2142 & 0 and 2 & 89.29 & - & 10.71 & 0.6299 \\
\hline Total by side & Right & 2.8571 & $0-9$ & & & & 2.2886 \\
\hline & Left & 2.8571 & $1-10$ & & & & 2.3838 \\
\hline Total & & 5.7143 & $1-19$ & & & 4.6096 \\
\hline
\end{tabular}

Abbreviation: LMS, Lund-Mackay score.

The score of the posterior ethmoid on the right side had a mean of 0.5357 (SD: 0.6929), varied between 0 and 2, and $57.14 \%$ of patients scored $0,32.14 \%$ scored 1 , and $10.71 \%$ scored 2 . The score of the posterior ethmoid on the left side had a mean of 0.4827 (SD: 0.6876 ), varied between 0 and 2 , and $60.71 \%$ of patients scored $0,28.57 \%$ scored 1 , and $10.71 \%$ scored 2 . The score of the sphenoid sinus on the right side had a mean of 0.3214 (SD: 0.4755), varied between 0 and 1 , and $67.86 \%$ of patients scored 0 , and $32.14 \%$ scored 1 . The score of the sphenoid sinus on the left side had a mean of 0.3214 (SD: 0.4745 ), varied between 0 and 1 , and $67.86 \%$ of patients scored 0 , and $32.14 \%$ scored 1 . The score of the frontal sinus on the right side had a mean of 0.3571 (SD: 0.5587 ), varied between 0 and 2 , and $67.86 \%$ of patients scored $0,28.57 \%$ scored 1 , and $3.57 \%$ scored 2 . The score of the frontal sinus on the left side had a mean of 0.3928 (SD: 0.6288 ), varied between 0 and 2 , and $67.86 \%$ of patients scored $0,25 \%$ scored 1 , and $7.14 \%$ scored 2 . The score of the osteomeatal complex on the right side had a mean of 0.2857 (SD: 0.7127 ), varied from 0 to 2, and $85.71 \%$ of patients scored 0 , and $14.29 \%$ scored 2 . Finally, the score of the osteomeatal complex in the left side had a mean of 0.2142 (SD: 0.6299 ), varied from 0 to 2 , and $89.29 \%$ of patients scored 0 , and $10.71 \%$ scored 2 .

Another way to present the results of the LMS is distributing them in score categories, as shown in - Table 5. A total of 15 patients $(53.57 \%)$ were classified in the category from 0 to 4 points; 8 patients (28.57\%) were classified in the category from 5 to 9 points; 3 patients (10.71\%) were classified in the category from 10 to 14 points; and 2 patients (7.14\%) were classified in the category from 15 to 24 points .

\section{Discussion}

Chronic rhinosinusitis has made many patients who have exhausted all clinical therapeutic arsenal be submitted to FESS. However, $\sim 20 \%$ of patients do not exhibit significant improvement after surgery, and may require the RESS. ${ }^{3}$ Some causes for failure in the primary surgery have been identified, but there are still only a few studies in the literature investigating the radiological findings related to RESS. In the 90's, Kennedy noticed that patients with bilateral ethmoid disease involving two other sinus on each side and patients with diffuse polyps did not have a good clinical evolution after the FESS. ${ }^{12}$ Lazar et al verified that the most common cause for failure of the primary surgery was fibrosis and adhesion between the middle and lateral nasal turbinates. ${ }^{13}$ Other causes of failure found by this study were recurrent polyps, middle nasal turbinate lateralization, frontal recess obstruction, persistent uncinate process, persistent Agger nasi cells, and severe septal deviation. $^{13}$

As Musy and Kountakis pointed out, FESS has two main objectives: removing anatomical structures that may be blocking the drainage of the sinuses, and the preservation of a normal mucosa. ${ }^{14}$ Thus, it is possible to analyze the causes of failure in the primary surgery by the analysis of the FESS goals that were not accomplished. About the resection of structures, the present study found residual Haller cells in $7.14 \%$ of patients, whereas the study by Khalil et al found them in $25.4 \%$ of patients. ${ }^{11}$ The residual Haller cells may be a source of persistent obstruction of the maxillary sinus, which hampers a satisfactory result from the FESS. Thus, as the present study demonstrated 
Table 4 Individual results of each patient in the LMS $(n=28)$

\begin{tabular}{|c|c|c|c|c|c|c|c|c|c|c|c|c|}
\hline \multirow[t]{2}{*}{ Patient } & \multicolumn{2}{|c|}{ Frontal } & \multicolumn{2}{|c|}{$\begin{array}{l}\text { Anterior } \\
\text { ethmoid }\end{array}$} & \multicolumn{2}{|c|}{$\begin{array}{l}\text { Posterior } \\
\text { ethmoid }\end{array}$} & \multicolumn{2}{|c|}{ Maxillary } & \multicolumn{2}{|c|}{ Sphenoidal } & \multicolumn{2}{|c|}{$\begin{array}{l}\text { Osteomeatal } \\
\text { complex }\end{array}$} \\
\hline & $\mathrm{R}$ & L & $\mathrm{R}$ & L & $\mathbf{R}$ & L & $\mathbf{R}$ & $\mathrm{L}$ & $\mathbf{R}$ & L & $\mathbf{R}$ & $\mathrm{L}$ \\
\hline 1 & 1 & 1 & 1 & 1 & 1 & 1 & 1 & 1 & 1 & 1 & 0 & 0 \\
\hline 2 & 0 & 0 & 0 & 0 & 0 & 0 & 0 & 1 & 0 & 0 & 0 & 0 \\
\hline 3 & 0 & 0 & 0 & 0 & 0 & 0 & 1 & 1 & 0 & 0 & 0 & 0 \\
\hline 4 & 0 & 0 & 0 & 0 & 0 & 0 & 1 & 1 & 0 & 0 & 0 & 0 \\
\hline 5 & 1 & 1 & 1 & 0 & 0 & 0 & 1 & 1 & 0 & 1 & 2 & 0 \\
\hline 6 & 0 & 0 & 1 & 1 & 1 & 1 & 1 & 1 & 0 & 0 & 0 & 0 \\
\hline 7 & 1 & 1 & 0 & 0 & 0 & 0 & 0 & 0 & 0 & 0 & 0 & 0 \\
\hline 8 & 1 & 1 & 1 & 1 & 1 & 1 & 1 & 1 & 0 & 0 & 2 & 2 \\
\hline 9 & 0 & 0 & 1 & 1 & 1 & 1 & 1 & 1 & 1 & 0 & 0 & 2 \\
\hline 10 & 0 & 0 & 1 & 1 & 2 & 2 & 0 & 0 & 0 & 0 & 0 & 0 \\
\hline 11 & 0 & 0 & 0 & 0 & 0 & 0 & 1 & 1 & 0 & 0 & 0 & 0 \\
\hline 12 & 0 & 0 & 1 & 1 & 0 & 0 & 0 & 0 & 0 & 0 & 0 & 0 \\
\hline 13 & 0 & 0 & 0 & 0 & 0 & 0 & 1 & 1 & 0 & 0 & 0 & 0 \\
\hline 14 & 1 & 1 & 0 & 0 & 0 & 0 & 1 & 1 & 1 & 1 & 0 & 0 \\
\hline 15 & 0 & 0 & 1 & 2 & 1 & 1 & 2 & 1 & 0 & 0 & 0 & 0 \\
\hline 16 & 0 & 0 & 0 & 0 & 1 & 0 & 1 & 1 & 0 & 0 & 0 & 0 \\
\hline 17 & 0 & 0 & 1 & 1 & 1 & 1 & 0 & 1 & 0 & 0 & 0 & 0 \\
\hline 18 & 0 & 0 & 0 & 0 & 0 & 0 & 1 & 1 & 0 & 0 & 0 & 0 \\
\hline 19 & 0 & 0 & 0 & 0 & 0 & 0 & 1 & 1 & 1 & 1 & 0 & 0 \\
\hline 20 & 1 & 2 & 2 & 2 & 2 & 2 & 1 & 1 & 1 & 1 & 2 & 2 \\
\hline 21 & 0 & 0 & 0 & 0 & 0 & 0 & 1 & 1 & 0 & 0 & 0 & 0 \\
\hline 22 & 1 & 2 & 2 & 2 & 2 & 2 & 1 & 1 & 1 & 1 & 0 & 0 \\
\hline 23 & 0 & 0 & 0 & 0 & 0 & 0 & 1 & 1 & 1 & 0 & 0 & 0 \\
\hline 24 & 2 & 1 & 1 & 1 & 1 & 1 & 0 & 1 & 0 & 1 & 0 & 0 \\
\hline 25 & 0 & 0 & 0 & 0 & 0 & 0 & 1 & 1 & 0 & 0 & 0 & 0 \\
\hline 26 & 1 & 1 & 1 & 1 & 1 & 1 & 1 & 1 & 1 & 1 & 2 & 0 \\
\hline 27 & 0 & 0 & 0 & 0 & 0 & 0 & 1 & 1 & 0 & 0 & 0 & 0 \\
\hline 28 & 0 & 0 & 0 & 0 & 0 & 0 & 1 & 1 & 1 & 1 & 0 & 0 \\
\hline
\end{tabular}

Abbreviations: L, left; LMS, Lund-Mackay score; R, right.

lower rates of this residual anatomical structure, it is possible to say that the studied population was less exposed to a factor that predisposes clinical failure after surgery.

Table 5 Distribution of patients according to score categories in the LMS $(n=28)$

\begin{tabular}{|l|l|l|}
\hline $\begin{array}{l}\text { Score } \\
\text { category }\end{array}$ & N & $\%$ \\
\hline $0-4$ & 15 & 53.57 \\
\hline $5-9$ & 8 & 28.57 \\
\hline $10-14$ & 3 & 10.71 \\
\hline $15-24$ & 2 & 7.14 \\
\hline
\end{tabular}

Abbreviation: LMS, Lund-Mackay score.
The uncinate process was found in all patients in this study, either in its normal form (92.85\% of patients) or residual form (7.14\% of the patients). These rates are different from those found by Khalil et al and Musy and Kountakis, who found a residual uncinate process in $60.3 \%$ and $37 \%$ of patients respectively. ${ }^{11,14}$ This finding indicates more preservation of this structure during primary surgery in the population from this study when compared with the one from other studies. There is a disagreement in the literature about what is the best conduct to be taken regarding the uncinate process in the FESS. Some studies say that the resection of the uncinate process is an important step in the maxillary sinusectomy. ${ }^{15}$ Parsons et al described the "missed ostium sequence," caused by the incomplete removal of the uncinate process, as the most important cause of failure in the FESS. ${ }^{16}$ This sequence is caused by the modification of the maxillary sinus ostium position that results in a recirculation phenomenon, in which the mucus circulates outside the natural ostium and returns to the sinus 
by the middle meatus antrostomy. This process results in the obstruction of the maxillary sinus and in the return of the symptoms as a consequence. ${ }^{14,16}$ Other studies, such as the one conducted by Nayak et al, defend the idea that the uncinate process must be preserved in the FESS. The reason would be the functional role of protecting the sinus against allergens and bacteria, acting as a physical barrier and directing the contaminated air out of the sinus. ${ }^{17}$

The second main objective of the FESS is the preservation of the sinus normal mucosa, and its importance is well established in the literature. The non-fulfilment of this principle may lead to scarring in areas around the sinusotomies and even to middle nasal turbinate lateralization. ${ }^{14}$ This study found middle nasal turbinate lateralization in $10.71 \%$ of patients. This percentage is lower than the ones found by Khalil et al and Musy and Kountakis, who found it in $17.5 \%$ and $78 \%$ of patients respecively. ${ }^{11,14}$ This may represent a more careful handling of the mucosa in the primary surgery of the patients from this population compared with the ones from other studies. Another important cause of middle turbinate lateralization is the resection, even if partial, of the middle turbinate tissue. This procedure must be reserved for a few selected cases, as for patients with large pneumatization areas in the middle turbinate. ${ }^{14}$ Signs of middle nasal turbinate resection were found in $10.71 \%$ of patients. Even though this rate of patients does not represent a large portion of this study's population, it is not known if the resection was necessary in these cases, and there is no viable similar data in the literature for us to compare.

Some findings were observed in a significant number of patients in the literature, but were not identified in this study, or were identified in a small number of patients. In the study by Khalil et al, residual cells in the posterior ethmoid were found in $96.8 \%$ of patients, and residual cells in the anterior ethmoid were found in $92.1 \%$ of them. The study by Musy and Kountakis found residual Agger nasi cells in 49\% of patients, residual cells in the anterior ethmoid in $64 \%$, and residual cells in the ethmoid posterior in $41 \%$ of them. ${ }^{14}$ The present study found residual ethmoidal cells in only $3.57 \%$ of patients. However, $46.42 \%$ had no signs of manipulation in the ethmoid sinus. This demonstrates the absence of resection in this structure, resulting in residual ethmoid cells. Despite the fact that our rates were lower when compared to other studies, residual ethmoidal cells were observed in a significant number of patients in the present study. This shows the preference for more conservative techniques, which may have been determinant in the surgery failure in these cases.

The study by Musy and Kountakis also found obliteration in frontal recesses in $50 \%$ of patients, and stenosis of the middle meatus antrostomy in $39 \%$ of them. ${ }^{14}$ The study by Khalil et al found residual cells in the frontal recess in $96.8 \%$ of patients, and obstruction of the ostium of the sphenoid sinus in $68.3 \%$ of them. ${ }^{11}$ This study identified the middle nasal turbinate lateralization with stenosis of the middle meatus in $10.71 \%$ of patients. This is a common complication, and often requires RESS to unlock the middle meatus. The present study also found frontal recess obliteration in $25 \%$ of patients, and obliteration of the sphenoethmoidal recess in $14.28 \%$ of them. These findings were identified less frequently in this study when compared to the studies conducted by Khalil et al and Musy and Kountakis. However, all of these results suggest the use of conservative techniques in the resection of structures related to the FESS.

Among the most frequent findings observed in the present study, the remaining septal deviation was found in $75 \%$ of patients. This datum contrasts with the findings of the study by Khalil et al, in which septal deviation was identified in only $15.9 \%$ of patients. ${ }^{11}$ Other significant findings observed in this study were not found in similar studies, ${ }^{11,14}$ such as: the mucosal thickening of the maxillary sinus in $89.28 \%$ of patients; the absence of manipulation signs in the inferior nasal turbinate in $85.71 \%$ of patients; the absence of manipulation signs in the osteomeatal complex in $75 \%$ of patients; the absence of manipulation signs in the frontal sinus in $64.28 \%$ of patients; the absence of manipulation signs in the sphenoid sinus in $60.71 \%$ of patients; mucosal thickening of the ethmoid sinus in $50 \%$ of patients; the absence of manipulation signs in the ethmoid sinus in $46.42 \%$ of patients; the pneumatization of the middle nasal turbinate in $39.28 \%$ of patients; the absence of manipulation signs in the middle nasal turbinate in $39.28 \%$ of patients; and mucosal thickening of the sphenoid sinus in $39.28 \%$ of patients.

The LMS was the method used to stage the severity of the CRS. ${ }^{18}$ According to the study by Ashraf and Bhattacharyya, this score may range from 0 to 5 , even in a clinically normal population. They also proposed that a minimum score of 4 was necessary to perform the FESS. ${ }^{19}$ However, in the study by Hopkins et al, $20.9 \%$ of patients undergoing FESS scored between 0 and 4 . This highlights that the symptom intensity must be the most important factor in the therapeutic decision. In the remaining score categories, $25.5 \%$ of patients scored between 5 and 9; 28\% scored between 10 and 14 ; and $25.6 \%$ of patients scored between 15 and 24 . The mean score found by Hopkins et al was 7 (SD: 4.7). ${ }^{20}$ The present study obtained a mean of 5.71 (SD: 4.60) in the LMS, and most patients fell into the lowest score categories. However, in the study by Hopkins et al, only $36.3 \%$ out of 848 patients undergoing FESS by CRS were submitted to reoperations. ${ }^{20}$ Thus, the population studied by Hopkins et al was not a homogeneous one, unlike the one in the present study.

The study by Khalil et al found pansinusitis in most patients undergoing RESS using the LMS; wherein scored 0 only $2.4 \%, 7.1 \%$ and $22.2 \%$ of maxillary, ethmoidal and frontal sinuses respectively. Based on this, the authors suggest that more aggressive dissections should have been used in the primary surgery of those patients. ${ }^{11}$ In the present study, $5.35 \%$ of patients scored 0 for the maxillary sinus, $13.39 \%$ scored 0 for the ethmoidal sinus, and $33.9 \%$ scored the same for the frontal sinus. This suggests that less conservative techniques were used in the primary surgery for this study's population when compared to the study by Khalil et al. ${ }^{11}$ Thus, it is possible to verify that the present study obtained lower rates in the LMS when compared to similar studies. ${ }^{11,20}$ 
The most studied discussion point about the tomographical findings of RESS in the literature is the use of more aggressive or more conservative techniques of resection. While some authors argue that aggressive resections would be essential to avoid failure in the FESS, others believe that the conservation of normal tissues in the sinus is the key to a good clinical outcome. According to the analysis of some structures in the present study, it is possible to infer that more conservative resection techniques were applied. Still, the number of residual structures found was very large, and some of them are related to failure in the FESS. A possible explanation for the adequate resection not having occurred during the primary surgery may be the lack of request of a preoperative CT scan for surgical planning. As the present study did not aim to assess the clinical outcome of RESS and did not have a control group, it is not possible to draw definitive conclusions. However, it is expected that, with the identification of residual structures from the FESS that may lead to clinical failure, other studies should be performed to correlate the different resection techniques with their clinical outcomes.

The present study suggests that the lack of request of a preoperative CT scan during primary surgeries may have interfered in the decision to use more conservative techniques in these patients, which resulted in the persistence of residual structures. So, one of the possibilities to explain the choice for more conservative surgical techniques that resulted in the persistence of structures that should have been removed is the lack of a CT scan during the preoperative planning. It is already well established in the literature that CT is the best imaging technique for the evaluation of patients affected by CRS. ${ }^{1}$ Nevertheless, the experience with this study reinforced the fundamental role that CT plays in the diagnosis and therapeutic decision in cases of RESS.

\section{Conclusion}

The CT analysis in patients undergoing RESS showed findings that may be responsible for the failure of the primary surgery, with the persistence of symptoms. These findings are the result of excessive resection or the lack of it, keeping persistent structures, in previous FESS. The most significant findings were: the presence of residual septal deviation; middle nasal turbinate lateralization; a residual or not resected uncinate process; residual Haller cells; mucosal thickening of the frontal, ethmoidal, sphenoidal and maxillary sinuses; and the absence of surgical manipulation signs in these same sinuses. The level of mucosal thickening of the sinuses was verified using the LMS, and the average score was 5.71. Most patients were classified in the lower score category, between 0 and 4 points. Studies comparing the technical variants with clinical outcomes should be performed to confirm the results.

\section{References}

1 Brasileiras de Rinossinusites DRev Bras Otorrinolaringol [Internet]. 2008;74(2 Suppl):6-59. Available in: http://dx.doi.org/ 10.1590/S0034-72992008000700002. Acessed in May 14, 2015

2 Huang BY, Lloyd KM, DelGaudio JM, Jablonowski E, Hudgins PA. Failed endoscopic sinus surgery: spectrum of CT findings in the frontal recess. Radiographics 2009;29(01):177-195

3 Govindaraj S, Agbetoba A, Becker S. Revision sinus surgery. Oral Maxillofac Surg Clin North Am 2012;24(02):285-293, ix

4 Masterson L, Agalato E, Pearson C. Image-guided sinus surgery: practical and financial experiences from a UK centre 2001-2009. J Laryngol Otol 2012;126(12):1224-1230

5 Cohen NA, Kennedy DW. Revision endoscopic sinus surgery. Otolaryngol Clin North Am 2006;39(03):417-435, vii

6 Mascarenhas JG, da Fonseca VM, Chen VG, et al. Long-term outcomes of endoscopic sinus surgery for chronic rhinosinusitis with and without nasal polyps. Rev Bras Otorrinolaringol (Engl Ed) 2013;79(03):306-311

7 Kountakis SE, Jacobs J, Gosepath J. Revision Sinus Surgery. $1^{\text {st }}$ ed. Berlin: Springer; 2008

8 Hopkins C, Browne JP, Slack R, et al. The national comparative audit of surgery for nasal polyposis and chronic rhinosinusitis. Clin Otolaryngol 2006;31(05):390-398

9 Okushi T, Nakayama T, Morimoto S, et al. A modified LundMackay system for radiological evaluation of chronic rhinosinusitis. Auris Nasus Larynx 2013;40(06):548-553

10 Lund VJ, Kennedy DW. Staging for rhinosinusitis. Otolaryngol Head Neck Surg 1997;117(3 Pt 2):S35-S40

11 Khalil HS, Eweiss AZ, Clifton N. Radiological findings in patients undergoing revision endoscopic sinus surgery: a retrospective case series study. BMC Ear Nose Throat Disord 2011;11:4

12 Kennedy DW. Prognostic factors, outcomes and staging in ethmoid sinus surgery. Laryngoscope 1992;102(12 Pt 2, Suppl 57)1-18

13 Lazar RH, Younis RT, Long TE, Gross CW. Revision functional endonasal sinus surgery. Ear Nose Throat J 1992;71(03):131-133

14 Musy PY, Kountakis SE. Anatomic findings in patients undergoing revision endoscopic sinus surgery. Am J Otolaryngol 2004;25(06): 418-422

15 Figueroa RE. Imaging Anatomy in Revision Sinus Surgery. Kountakis S, Jacobs J, Gosepath J. Revision Sinus Surgery. Berlin: Springer; 2008:1-10

16 Parsons DS, Stivers FE, Talbot AR. The missed ostium sequence and the surgical approach to revision functional endoscopic sinus surgery. Otolaryngol Clin North Am 1996;29(01):169-183

17 Nayak DR, Balakrishnan R, Murty KD. Functional anatomy of the uncinate process and its role in endoscopic sinus surgery. Indian J Otolaryngol Head Neck Surg 2001;53(01):27-31

18 Lund VJ, Mackay IS. Staging in rhinosinusitus. Rhinology 1993; 31(04):183-184

19 Ashraf N, Bhattacharyya N. Determination of the "incidental" Lund score for the staging of chronic rhinosinusitis. Otolaryngol Head Neck Surg 2001;125(05):483-486

20 Hopkins C, Browne JP, Slack R, Lund V, Brown P. The Lund-Mackay staging system for chronic rhinosinusitis: how is it used and what does it predict? Otolaryngol Head Neck Surg 2007;137(04): 555-561 